\title{
Assessment of venous Doppler ultrasound findings of acute unilateral lower limb swelling in a tertiary facility in central Ghana: a retrospective analytical study
}

Emmanuel Kobina Mesi Edzie ${ }^{1,2^{*}} \mathbb{D}$, Klenam Dzefi-Tettey ${ }^{3}$, Edmund Kwakye Brakohiapa ${ }^{4}$, Philip Narteh Gorleku', Frank Naku Ghartey ${ }^{5}$, Adu Tutu Amankwa6, Peter Appiah-Thompson7, Michael Kofi Amedi ${ }^{8}$, Ewurama Andam Idun ${ }^{8}$, Madison Adanusa ${ }^{9}$, Obed Cudjoe ${ }^{10}$, Evans Boadi², Joshua Mensah Kpobi²,

Frank Quarshie ${ }^{11}$, Richard Ato Edzie ${ }^{1}$ and Abdul Raman Asemah ${ }^{1}$ (i)

\begin{abstract}
Background: Unilateral lower limb swelling has wide differential diagnoses with varying treatment plans, requiring an early and accurate diagnosis. Doppler ultrasound offers an extensive examination of the vascular system providing a platform for diagnosis and avoidance of unnecessary invasive procedures. Thus, it becomes pertinent to ensure that all the sonographic information required for the accurate diagnosis of a swollen lower limb is documented and critically analyzed in our setting, hence this study.

Results: The records of a total of 151 patients with acute unilateral lower limb swelling were retrieved, females constituted the majority (51.7\%). The overall mean age was $58.70 \pm 16.71$ years. Statistical significance was specified at $p \leq 0.05$ for this study. The males were on the average 1.86 years younger than the female, but this difference was not statistically significant $(p=0.495)$. Patients older than 60 years constituted the majority $72(47.7 \%)$ followed by the 40-60-year age category 61 (40.4\%), and the left lower limb was affected more often 82 (54.3\%). Multiple inguinal lymphadenopathy 82 (35.7\%) and edema with thickened skin and subcutaneous layers 67 (29.1\%) were the two most recurrent ultrasound features. There was no significant association between the sonographic features and the diagnoses made for acute unilateral lower limb swelling, except for the feature of edema with thickened skin and subcutaneous layers ( $p=0.004)$ and the diagnosis of cellulitis $(p=0.047)$ that increased significantly with age.

Conclusion: Multiple inguinal lymphadenopathy and edema of the skin and subcutaneous layers were the most recurrent ultrasound features with cellulitis as the main diagnosis for acute unilateral lower limb swelling in our setting. Edema with thickened skin and subcutaneous layers and cellulitis both increased significantly with age. Sonographers, sonologists, and radiologists must be on the look-out for these in their practices.
\end{abstract}

Keywords: Acute unilateral lower limb swelling, Venous Doppler ultrasound, Ghana

*Correspondence: emmanuel.edzie@ucc.edu.gh

${ }^{1}$ Department of Medical Imaging, School of Medical Sciences, College of Health and Allied Sciences, University of Cape Coast, Cape Coast,

Ghana

Full list of author information is available at the end of the article

\section{Introduction}

Unilateral lower limb swelling is a common, yet challenging condition encountered in clinical practice with significant impact. It is defined as the accumulation of excess interstitial fluid in the lower extremity that exceeds the capacity of physiologic lymphatic drainage, leading to 
swelling of the feet and extending upwards [1, 2]. Unilateral lower limb swelling generally results from deep vein thrombosis (DVT), lymphedema (soft tissue swelling), lipedema, venous insufficiency, localized venous compression, and venous hypertension [3, 4].

Aching, pain, heaviness, characteristic venous, or lymphatic skin changes such as healed or active ulcerations of the lower limb are some of the symptoms described for unilateral lower limb swelling $[4,5]$. Based on the onset of the limb swelling, unilateral lower limb swelling can be categorized into acute or chronic according to the duration of the condition; acute (three days or less), sub-acute (3 days-3 months), and chronic (more than three months) [2]. Acute unilateral lower limb swelling can be as a result of thrombophlebitis, especially with the presence of inflammation such as tenderness, increased warmth, and erythema. A more insidious development or chronic duration of unilateral lower limb swelling can be easily misdiagnosed as venous insufficiency. In actuality, such a presentation may be an atypical manifestation of an occult malignancy causing lymphatic or venous obstruction [6].

The goal of modern radiology practice and research is to transition from invasive to noninvasive diagnostic approaches [7]. The noninvasive methods now available for diagnosis and evaluation of clinical conditions include magnetic resonance imaging (MRI), computed tomography $(\mathrm{CT})$, impedance plethysmography (IPG), isotope venography, and Doppler ultrasound.

Although the presence of pain, its type, and the family history of disease can provide clues to the cause of edema, the position and localization of swelling, skin color, scarring, and abdominal findings can help ascertain the underlying pathology [4]. Accurate evaluation of the unilateral lower limb swelling is important to guide therapeutic decisions.

Venous Doppler ultrasound of the lower limbs is a well-established procedure, which includes the visualization of the venous and arterial system both in morphology and blood flow characteristics, especially as digital ultrasound has been reported as the most available in our setting. Several studies have reported that Doppler ultrasound has similar findings with venography and arteriography in the diagnosis of many venous and arterial diseases of the lower limb, respectively [8-11].

The introduction of Doppler ultrasound has now become the mainstay of lower limb venous assessment in patients. This safe, noninvasive, low-cost technique can be used to evaluate the lower extremities for vascular and non-vascular etiologies of both acute and chronic swelling and offers repeatability, reproducibility, high sensitivity, specificity, and positive predictive value for evaluation of valve function disorders and venous anatomy [10, 12, 13]. This study aimed at assessing the commonest findings of venous Doppler ultrasound in patients with acute unilateral lower limb swelling in a typical urban community in Ghana.

\section{Methods}

\section{Study site and design}

This was a retrospective study that reviewed and evaluated the venous Doppler ultrasound reports done for acute unilateral lower limb swellings of all the patients examined, from April 2017 to April 2021, at the ultrasound department of the Cape Coast Teaching Hospital (CCTH). For the period under consideration, a total of 151 patients underwent venous Doppler ultrasound examination for acute unilateral lower limb swelling in CCTH.

$\mathrm{CCTH}$ is the biggest public health facility in the central region of Ghana and located in the regional capital of Cape Coast. It offers high-quality tertiary and subspecialty services (including medical imaging services) to the inhabitants of the central region and the surrounding regions like the Greater Accra, Western, and Ashanti regions, and even beyond the borders of Ghana. It is a

Table 1 Characteristics of patients

\begin{tabular}{ll}
\hline Variable & Count (\%) \\
\hline Total count & 151 \\
Minimum & 17 \\
Maximum & 99 \\
Mean (standard deviation) & $58.70(16.71)$ \\
Age group & \\
$\quad \leq 18$ years & $2(1.3 \%)$ \\
19-39 years & $16(10.6 \%)$ \\
$40-60$ years & $61(40.4 \%)$ \\
$>60$ years & $72(47.7 \%)$ \\
Gender & \\
$\quad$ Male & $73(48.3 \%)$ \\
$\quad$ Female & $78(51.7 \%)$ \\
Type of lower limb affected & \\
$\quad$ Right lower limb & $69(45.7 \%)$ \\
Left lower limb & $82(54.3 \%)$ \\
\hline
\end{tabular}


Table 2 Average age comparison among sex of patients with acute unilateral lower limb swelling

\begin{tabular}{|c|c|c|c|c|c|c|}
\hline Gender & Mean & Standard deviation & Mean difference & $\begin{array}{l}95 \% \text { Cor } \\
\text { differen }\end{array}$ & erval of the & $P$ value \\
\hline Male & 57.73 & 16.75 & 1.864 & -7.244 & 3.517 & 0.495 \\
\hline Female & 59.59 & 16.69 & & & & \\
\hline
\end{tabular}

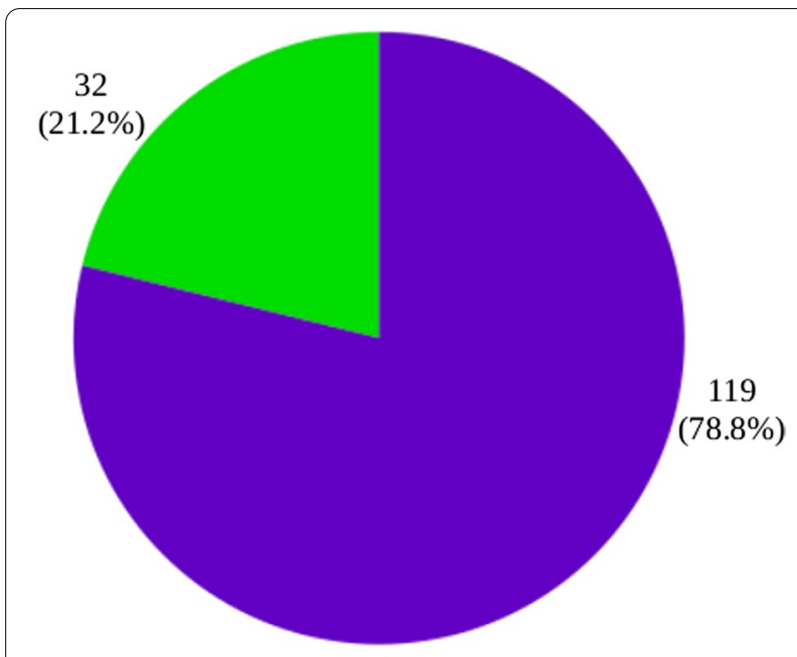

Normal Findings $\square$ Abnormal Findings

Fig. 1 Distribution of the state of findings from the venous Doppler ultrasound

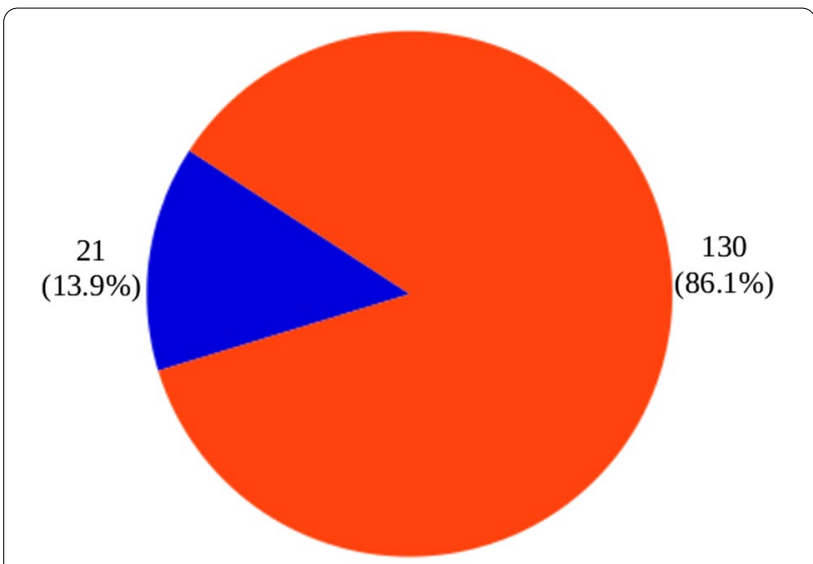

DVT as a Cause of Acute Unilateral Lower Limb Swelling - Other Causes of Acute Unilateral Lower Limb Swelling

Fig. 2 An overall assessment of DVT as a cause of acute unilateral lower limb swelling versus other causes center of excellence for the training of healthcare professionals, an accredited institution for the University of Cape Coast, School of Medical Sciences, and the Ghana College of Physicians and Surgeons for the training of medical doctors and specialists, respectively. It is also a lead research institution in Ghana.

\section{Data collection}

We reviewed the medical records to obtain the age and sex of all the patients examined for acute unilateral lower limb swelling based on the duration of symptoms from the Lightwave Health Information Management System (LHIMS). The ultrasound features and diagnosis made after the procedure were also retrieved from the ultrasound examination reports as well as the side (laterality) of the lower limb affected. The sonographic features obtained were categorized under the following themes: edema with thickened skin and subcutaneous layers, multiple inguinal lymphadenopathy, multiple popliteal lymphadenopathy, deep veins with intraluminal echoes or thrombi, deep veins with no flow on color Doppler, incompressible superficial veins, incompressible deep veins, dilated superficial tortuous veins, popliteal fossa thick-walled cystic mass or lesion, spectral augmentation on distal compression, distended superficial veins with intraluminal echoes or thrombi and lower limb ulceration. The diagnosis resulting from the ultrasound features was also sorted as inguinal lymphadenopathy, cellulitis, deep vein thrombosis, varicose veins, popliteal cyst or Baker's cyst, superficial thrombophlebitis, lower limb pyomyositis, and lymphatic obstruction by proximal lymph nodes.

The venous Doppler studies for the patients and the resultant reports were done by three radiologists of twelve years of experience in vascular Doppler imaging. The venous Doppler ultrasonography for the unilateral lower limb swelling was also performed using Toshiba Diagnostic Ultrasound System, Model Applio 300/TUSA300, 2013, with a 5.0-MHz linear probe, manufactured by Toshiba Medical Systems (Otawara, Tochigi, Japan). 


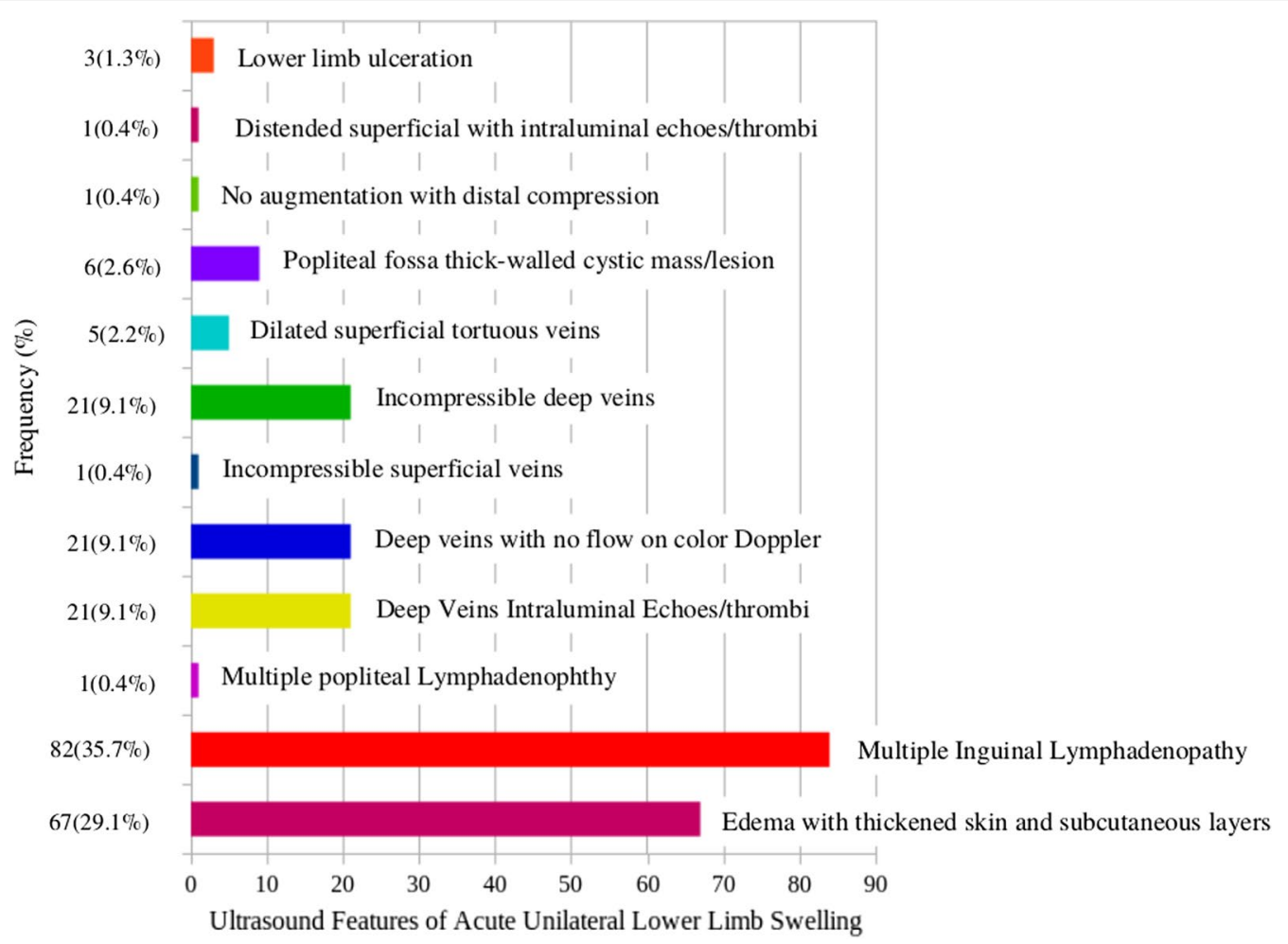

Fig. 3 Venous Doppler ultrasound features of patients with abnormal acute unilateral lower limb swelling

Data obtained for this study were consecutively retrieved from the records for the period under study, excluding Doppler examinations performed for patients without duration of symptoms from the LHIMS, chronic lower limb swellings, arterial and bilateral lower limb swellings.

\section{Statistical analysis}

Data obtained were organized, coded, and analyzed using the Statistical Package for Social Sciences (SPSS Inc., Chicago, IL, USA) version 20.0. The results obtained were presented in appropriate tables and charts using LibreOffice Calc (version 1:6.1.5-3+deb10u6 developed by The Document Foundation). The age and sex of our patients were compared to the sonographic features and diagnosis using a Chi-squared test. A similar association was also done between the laterality of the affected limb and the diagnosis made. An independent sample t-test was also employed to test for the difference between the average ages for acute unilateral lower limb swelling across the sexes. Statistical significance for this study was specified at $p \leq 0.05$. These were done in order to achieve the following specific objectives:

- To ascertain the socio-demographics of patients with acute unilateral lower limb swelling.

- To know the commonest venous Doppler imaging findings for acute unilateral lower limb swelling in our setting.

- To determine whether there is an association between age, sex, the laterality of the affected limb, and the venous Doppler findings for acute unilateral lower limb swelling.

\section{Results}

For the period under review, a total of one hundred and fifty-one venous ultrasound Doppler examinations were performed for acute unilateral lower limb swelling. Out of this, the female constituted the majority 


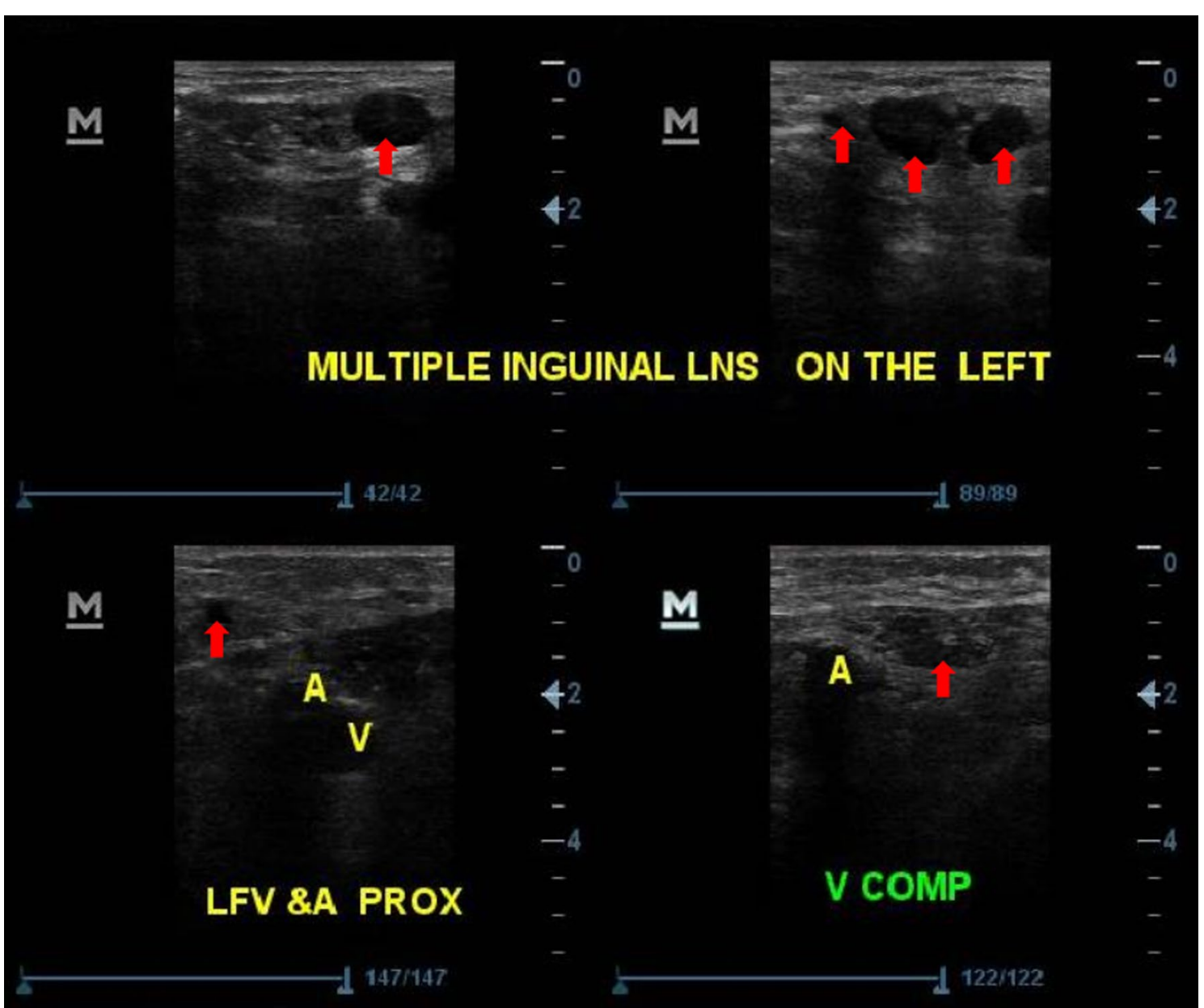

Fig. 4 Sonograms of a left lower limb performed for a 65-year-old female who reported with a two-day history of swelling of the left lower limb. It shows multiple hypoechoic rounded inguinal lymphadenopathies as shown by the red arrows. Also noted is a normal left deep femoral vein with complete compressibility

(51.7\%) of the patients. The average age for the patients examined was $58.70 \pm 16.71$ years with the age range observed between 17 and 99 years. The mean age for the males $(57.73 \pm 16.75$ years) was lower than that for the females (59.59 \pm 16.69 years); however, the difference between their mean ages was not statistically significant $(p=0.495)$. Patients in the above 60 -years age category constituted the majority $72(47.7 \%)$ followed by the 40-60-year age category 61 (40.4\%). Most of the patients $82(54.3 \%)$ examined presented with a swollen left lower limb. Detailed characteristics of the patients are presented in Tables 1 and 2.

Most of the patients 119 (78.8\%) examined had abnormal ultrasound findings, as depicted in Fig. 1.
Deep vein thrombosis contributed just few 21 (13.9\%) to the patients with acute unilateral lower limb swelling (Fig. 2). Figure 3 shows all the venous Doppler ultrasound features of patients with abnormal acute unilateral lower limb swelling in our study.

Multiple inguinal lymphadenopathy ultrasound feature (Fig. 4) and edema with thickened skin and subcutaneous layers (Fig. 5) were the two most common features observed with frequencies of 82 (35.7\%) and 67 (29.1\%), respectively, from this study. Deep veins with intraluminal echoes or thrombi (Fig. 6), incompressible deep veins (Fig. 6) and deep veins with no flow on color Doppler (Fig. 7) recorded the same frequencies of 21 


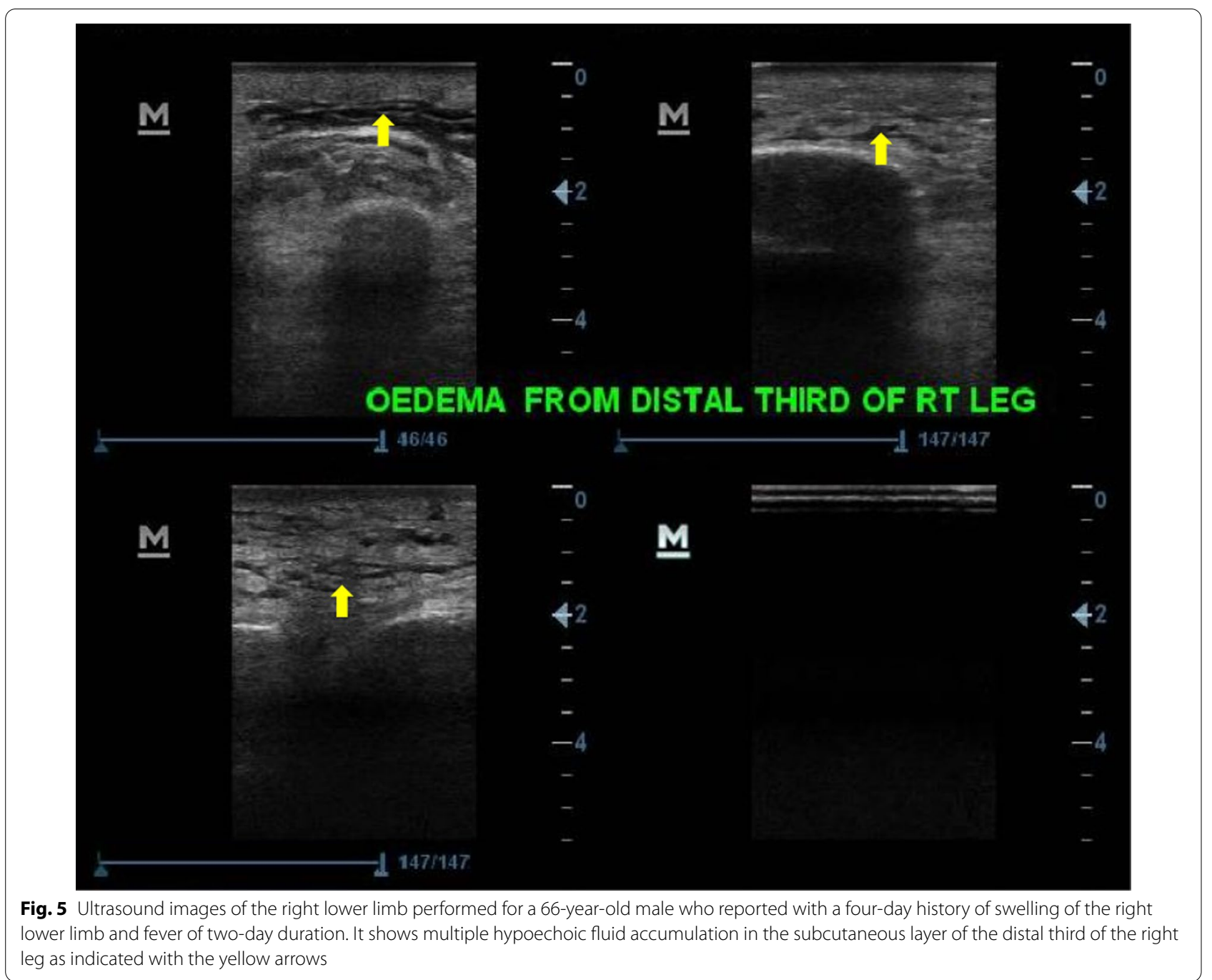

(9.1\%) for the third most prevalent feature. Other features observed in the patients can be seen in Fig. 3.

Cellulitis (Fig. 8), 47 (39.5\%), inguinal lymphadenopathy $33(27.7 \%)$, and deep vein thrombosis 21 (17.6\%) were the top three most dominant diagnoses, respectively. The rest are presented in Fig. 9.

On evaluation of the associations between the sonographic features with age, we found that edema with thickened skin and subcutaneous layers increased significantly with age $(p=0.004)$. The other sonographic features observed in the patients exhibited no significant association with the age groupings, and these findings are presented in Table 3.

Our analysis also revealed that the females dominated in almost all the sonographic features seen in our patients; however, gender had no significant association with any of the sonographic features observed (Table 4).

Cellulitis was seen to significantly increase with age $(p=0.047)$. Although the majority of the ultrasound diagnoses for venous Doppler examination increased with age, there were no significant associations between the patients' age groupings and the rest of the diagnoses made. These are presented in Table 5 .

Findings presented in Table 6 revealed that gender had no significant association with the venous Doppler ultrasound diagnoses.

Comparative analysis of the side of the affected lower limb and venous Doppler ultrasound diagnoses revealed no significant association. Detailed findings are presented in Table 7. 


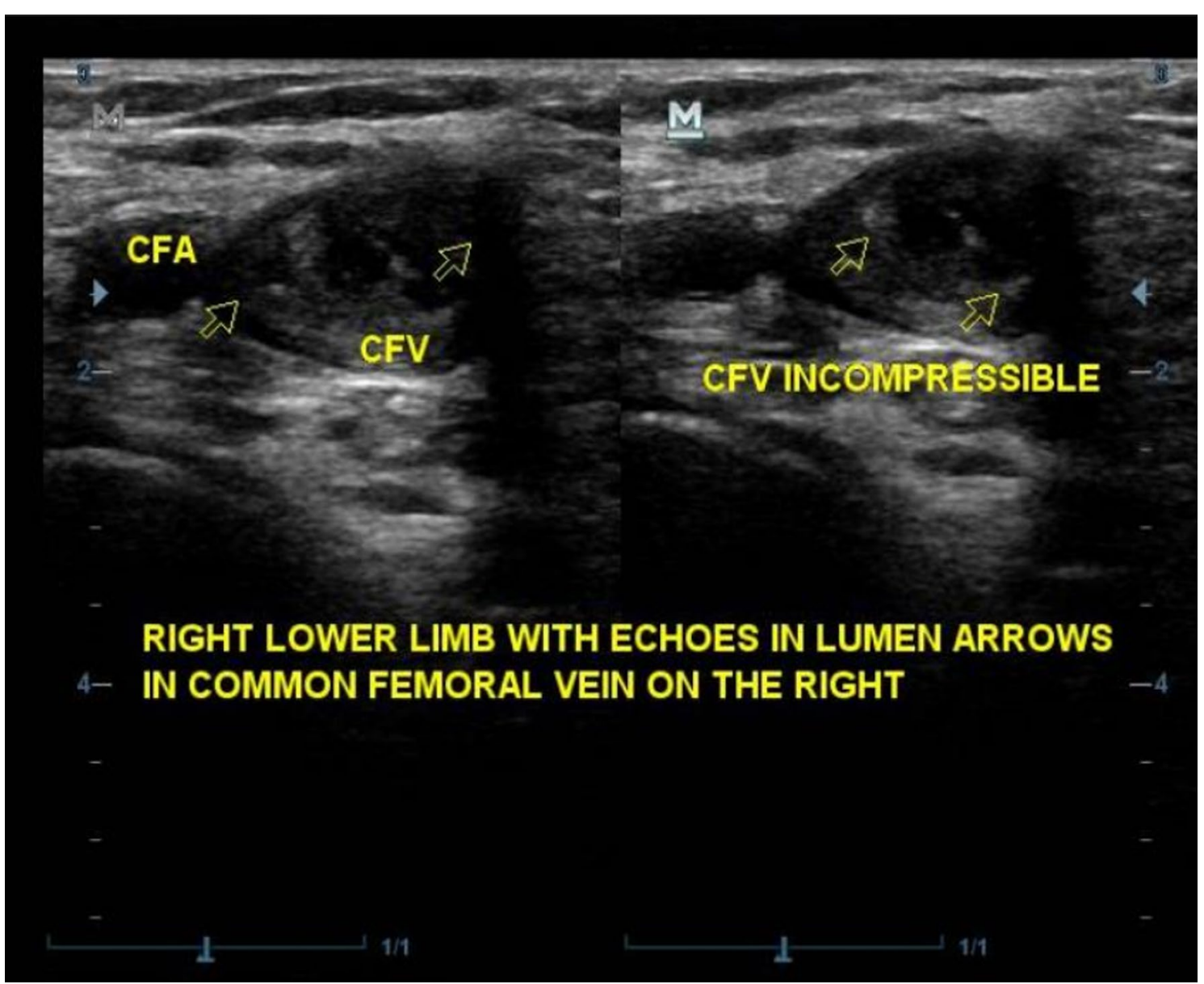

Fig. 6 Sonograms of the right lower limb performed for a 58-year-old woman who reported with a three-day history of significant swelling of the right lower limb and pain, after returning from a long-distance journey. It shows multiple hyperechoic intraluminal thrombi (yellow hollow arrows) and incompressible right common femoral vein indicative of an acute deep vein thrombosis of the right lower limb

\section{Discussion}

The emergence of Doppler ultrasound has vastly improved the assessment of the vascular system in health care globally. The ripple effect can be seen in the evaluation and management of acute unilateral lower limb swelling, which is commonly encountered in clinical practice, with deep vein thrombosis (DVT) often raised as the main diagnosis. However, studies have reported that, of the cases suspected clinically of DVT, $75 \%$ often have alternative diagnosis [14]. Analysis of our results revealed a much higher proportion $(86.1 \%)$ of the cases in our study resulting from other causes apart from DVT (Fig. 2). A study conducted by Aywak et al. to compare sonography with venography in the diagnosis of deep venous thrombosis reported a lower percentage (65.5\%) of their cases resulting from other causes apart from DVT [8]. Another study assessing the venous ultrasound testing for suspected thrombosis: incidence of significant non-thrombotic findings found that $91.0 \%$ of the cases were also as a result of other causes apart from DVT [15]. It is therefore imperative to be aware of other differential diagnosis of acute unilateral lower limb swelling to avoid unnecessary anticoagulation and potential misdiagnosis. This current study is arguably the first retrospective study on venous Doppler ultrasound features for acute unilateral lower limb swelling in our setting. 


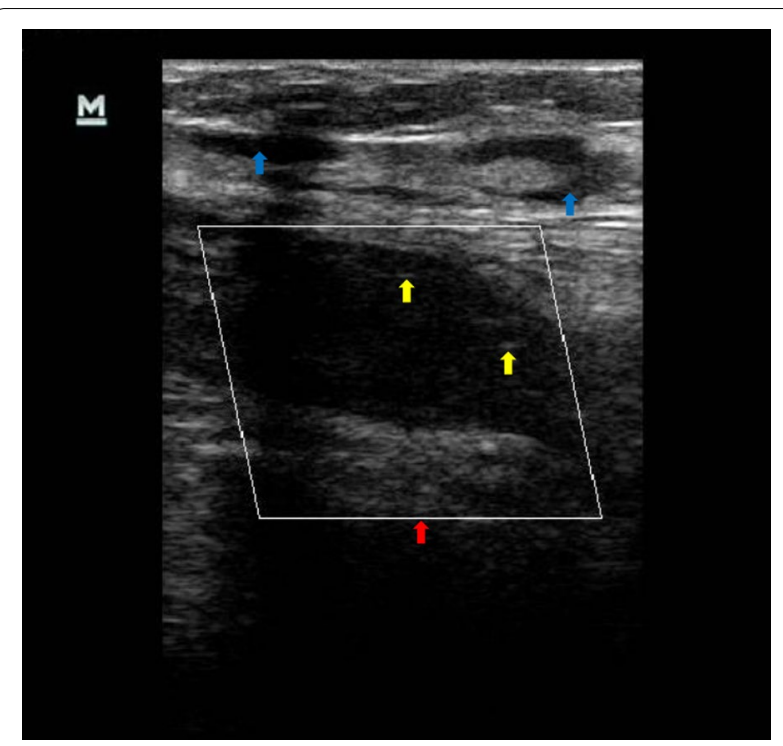

Fig. 7 An ultrasound image of the left lower limb performed for a 61-year-old woman who reported with a three-day history of swollen left lower limb and calf pain. It shows multiple intraluminal hyperechoic lesions (yellow arrows); no flow was noted within the distal third of the thigh vein (deep femoral) on color Doppler interrogation (red arrow) and associated multiple rounded inguinal lymphadenopathies as shown by the blue arrows

The average age of our studied population was estimated at 58.70 years (Table 1 ), a finding that is similar to an average age of 58.62 years reported by Hotoleanu et al's study assessing the correlations between clinical probability and Doppler ultrasound that results in the assessment of deep venous thrombosis [9]. Another study by Lockhart et al. also found a comparable mean age of 56.7 years in the patients they studied [16]. However, Sutter et al. reported a comparatively lower mean age of 49.6 years [15]. This mean age disparity across various studies cannot be readily explained; however, differences in demographics may be a possible contributing factor. In this current study, the distribution of our patients was seen to be increasing with age with the highest number of patients in the above 60-year age category (Table 1). This finding is corroborated by Khaladkar et al. who reported that the majority of the patients in their study were in the fifth decade [17]. Existing literature suggests the combined effect of wear and tear and reduced mobility in aging, as some of the main reasons for this phenomenon $[18,19]$. Further analysis of our results showed that even though the male patients were on the average 1.86 years younger than the females, the latter contributed to the majority of cases (Tables 1 and 2). A similar finding has been reported by Maheshwar et al. in India [20]. Older females usually develop osteoporosis as a result of menopause, which can lead to pathological fractures and subsequent immobility increasing the risk for lower limb swelling. Also, increase in intra-abdominal pressure as a result of pregnancy and pelvic masses may result in lower extremity swelling usually from venous stasis. The authors further posited that the long-term oral contraceptive use may be a predisposing factor for unilateral lower limb swelling in females [17].

The two most common venous Doppler ultrasound features in our study were multiple inguinal lymphadenopathy $82(35.7 \%)$ and edema of the skin and subcutaneous layers 67 (29.1\%), respectively (Fig. 3). Studies reviewing the role of venous Doppler ultrasound in unilateral lower limb swelling have reported an association with inguinal lymphadenopathies and edema with thickened skin and subcutaneous layers [18, 19, 21]. Sutter et al. also reported inguinal lymphadenopathy as the most common feature among the clinically significant minor incidental findings, which is similar to what we found. However, they recorded venous insufficiency as their second most common finding contrary to our findings [15]. Deep veins with no flow on color Doppler 21 (9.1\%), deep veins with intraluminal echoes/thrombi 21 (9.1\%) and incompressible deep veins 21 (9.1\%), which cumulatively resulted in the diagnosis of DVT, were the third observable features in this study (Figs. 6 and 7). These findings have been corroborated by several other studies [12, 22]. Edema of the skin and subcutaneous layers increased significantly with age $(p=0.004)$ (Table 3$)$; hence, sonographers, sonologists and radiologists must be on the lookout for this in the older patients. Most of the sonographic features in our study were more common among females than males as discussed earlier on. This could be due to females exhibiting more adiposities, which may trigger or be associated with chronic inflammatory responses with resultant changes in the vascular system $[23,24]$.

Our study further showed that cellulitis, inguinal lymphadenopathy and deep vein thrombosis were the three most common diagnoses from the venous Doppler ultrasound examinations undertaken (Fig. 9). Contrary to this, Sutter et al. reported DVT as the commonest abnormal finding in their study [15]. Furthermore, cellulitis 


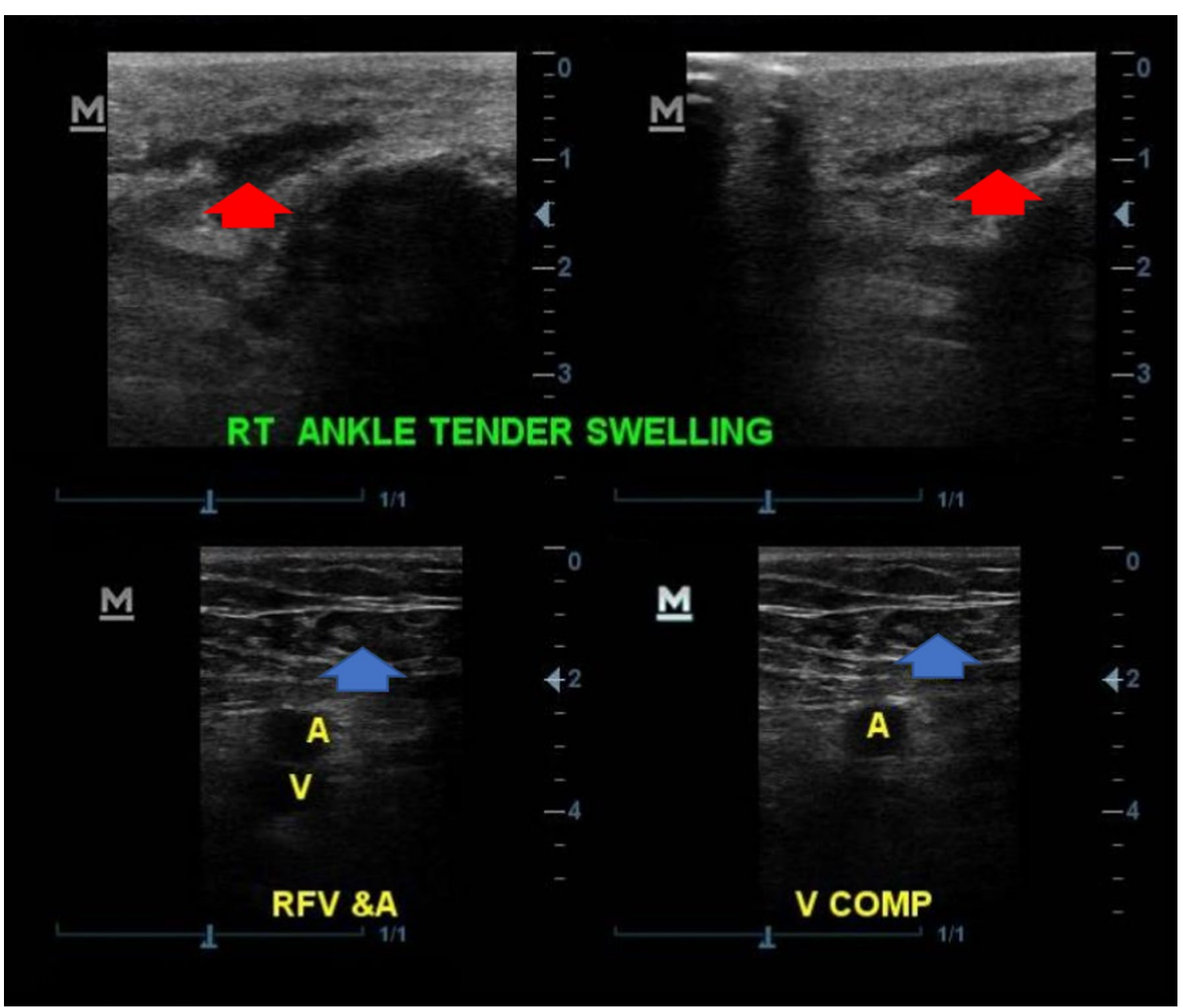

Fig. 8 Sonographic images of the right lower limb performed for a 47-year-old male with diabetes, who reported with a two-day history of swelling of the right lower limb (worst at the ankle) and fever of three-day duration. The demonstrated deep femoral veins are normal. It shows hypoechoic fluid collection in the subcutaneous layer of the right ankle as indicated with the red arrows and associated multiple inguinal lymphadenopathies (blue arrows) ultimately diagnosed as cellulitis

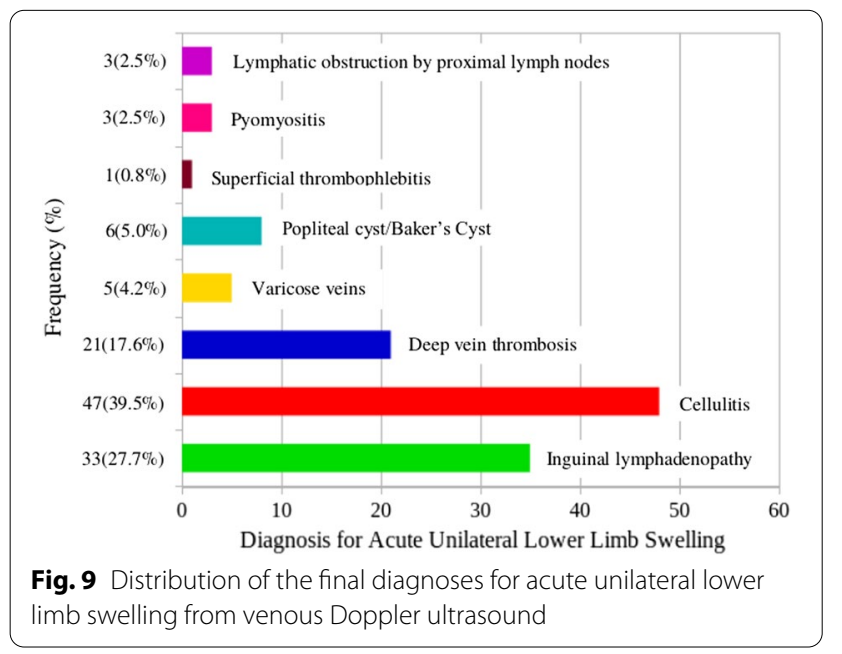

exhibited a significant association with age $(p=0.047)$ (Table 5). This is commonly seen among patients with diabetes mellitus, which has been reported to be on the increase in our setting [25]. Unilateral lower limb swelling on the left side was more common in this study, 
Table 3 Distribution showing the relationship between age and the ultrasound features of the patients

\begin{tabular}{|c|c|c|c|c|c|}
\hline Variable & Age group & & & & \\
\hline Features & $\leq 18$ years & $\begin{array}{l}19- \\
39 \text { years }\end{array}$ & $\begin{array}{l}40- \\
60 \text { years }\end{array}$ & $>60$ years & $P$ value \\
\hline
\end{tabular}

Edema with thickened skin and subcutaneous layers

$\begin{array}{cccccc}\text { Yes } & 0(0.0 \%) & 2(3.0 \%) & 24(35.8 \%) & 41(61.2 \%) & \mathbf{0 . 0 0 4}^{*} \\ \text { No } & 2(2.4 \%) & 14(16.7 \%) & 37(44.0 \%) & 31(36.9 \%) & \end{array}$

Multiple inguinal lymphadenopathy

$\begin{array}{llllll}\text { Yes } & 0(0.0 \%) & 6(7.1 \%) & 32(39.0 \%) & 44(53.7 \%) & 0.131\end{array}$

No $\quad 2(2.9 \%) \quad 10(14.5 \%) \quad 29(42.0 \%) \quad 28(40.6 \%)$

Multiple popliteal lymphadenopathy

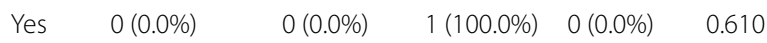

No $\quad 2(1.3 \%) \quad 16(10.7 \%) \quad 60(40.0 \%) \quad 72(48.0 \%)$

Deep veins with intraluminal echoes/thrombi

$$
\begin{array}{llccrr}
\text { Yes } & 0(0.0 \%) & 2(9.5 \%) & 10(47.6 \%) & 9(42.9 \%) & 0.789 \\
\text { No } & 2(1.5 \%) & 14(10.8 \%) & 51(39.2 \%) & 63(48.5 \%) &
\end{array}
$$

Deep veins with no flow on color Doppler

$$
\begin{array}{llllr}
\text { Yes } & 0(0.0 \%) & 2(9.5 \%) & 10(47.6 \%) & 9(42.9 \%) \\
\text { No } & 2(1.5 \%) & 14(10.8 \%) & 51(39.2 \%) & 63(48.5 \%)
\end{array}
$$

Incompressible superficial veins

$$
\begin{array}{lccccc}
\text { Yes } & 0(0.0 \%) & 0(0.0 \%) & 0(0.0 \%) & 1(100.0 \%) & 0.685 \\
\text { No } & 2(1.3 \%) & 16(10.7 \%) & 61(40.7 \%) & 71(47.3 \%) &
\end{array}
$$

Incompressible deep veins

$$
\begin{array}{lcccrr}
\text { Yes } & 0(0.0 \%) & 2(9.5 \%) & 10(47.6 \%) & 9(42.9 \%) & 0.789 \\
\text { No } & 2(1.5 \%) & 14(10.8 \%) & 51(39.2 \%) & 63(48.5 \%) &
\end{array}
$$

Dilated superficial tortuous veins

$$
\begin{array}{lccrrr}
\text { Yes } & 0(0.0 \%) & 0(0.0 \%) & 2(40.0 \%) & 3(60.0 \%) & 0.714 \\
\text { No } & 2(1.4 \%) & 16(11.0 \%) & 59(40.4 \%) & 69(47.3 \%) &
\end{array}
$$

\begin{tabular}{|c|c|c|c|}
\hline \multirow{2}{*}{$\begin{array}{l}\text { Variable } \\
\text { Features }\end{array}$} & \multicolumn{3}{|l|}{ Sex } \\
\hline & Male & Female & $P$ value \\
\hline \multicolumn{4}{|c|}{ Edema with thickened skin and subcutaneous layers } \\
\hline Yes & $32(47.8 \%)$ & $35(52.2 \%)$ & \multirow[t]{2}{*}{0.898} \\
\hline No & $41(48.8 \%)$ & $43(51.2 \%)$ & \\
\hline \multicolumn{4}{|c|}{ Multiple inguinal lymphadenopathy } \\
\hline Yes & $41(40.0 \%)$ & $41(50.0 \%)$ & \multirow[t]{2}{*}{0.657} \\
\hline No & $32(46.4 \%)$ & $37(53.6 \%)$ & \\
\hline \multicolumn{4}{|c|}{ Multiple popliteal lymphadenopathy } \\
\hline Yes & $0(0.0 \%)$ & $1(100.0 \%)$ & \multirow[t]{2}{*}{0.249} \\
\hline No & $73(48.7 \%)$ & $77(51.3 \%)$ & \\
\hline \multicolumn{4}{|c|}{ Deep veins intraluminal echoes/thrombi } \\
\hline Yes & $8(38.1 \%)$ & $13(61.9 \%)$ & \multirow[t]{2}{*}{0.311} \\
\hline No & $65(50.0 \%)$ & $65(50.0 \%)$ & \\
\hline \multicolumn{4}{|c|}{ Deep veins with no flow on color Doppler } \\
\hline Yes & $8(38.1 \%)$ & $13(61.9 \%)$ & \multirow[t]{2}{*}{0.311} \\
\hline No & $65(50.0 \%)$ & $65(50.0 \%)$ & \\
\hline \multicolumn{4}{|c|}{ Incompressible superficial veins } \\
\hline Yes & $1(100.0 \%)$ & $0(0.0 \%)$ & \multirow[t]{2}{*}{0.227} \\
\hline No & $72(48.0 \%)$ & $78(52.0 \%)$ & \\
\hline \multicolumn{4}{|c|}{ Incompressible deep veins } \\
\hline Yes & $8(38.1 \%)$ & $13(61.9 \%)$ & \multirow[t]{2}{*}{0.309} \\
\hline No & $65(50.0 \%)$ & $65(50.0 \%)$ & \\
\hline \multicolumn{4}{|c|}{ Dilated superficial tortuous veins } \\
\hline Yes & $2(40.0 \%)$ & $3(60.0 \%)$ & \multirow[t]{2}{*}{0.703} \\
\hline No & $71(48.6 \%)$ & $75(51.4 \%)$ & \\
\hline \multicolumn{4}{|c|}{ Popliteal fossa thick-walled cystic mass/lesion } \\
\hline Yes & $2(33.3 \%)$ & $4(66.7 \%)$ & \multirow[t]{2}{*}{0.448} \\
\hline No & $71(49.0 \%)$ & $74(51.0 \%)$ & \\
\hline \multicolumn{4}{|c|}{ No augmentation with distal compression } \\
\hline Yes & $1(100.0 \%)$ & $0(0.0 \%)$ & \multirow[t]{2}{*}{0.227} \\
\hline No & $72(48.0 \%)$ & $78(52.0 \%)$ & \\
\hline \multicolumn{4}{|c|}{ Distended superficial veins with intraluminal echoes/thrombi } \\
\hline Yes & $1(100.0 \%)$ & $0(0.0 \%)$ & \multirow[t]{2}{*}{0.227} \\
\hline No & $72(48.0 \%)$ & $78(52.0 \%)$ & \\
\hline \multicolumn{4}{|c|}{ Lower limb ulceration } \\
\hline Yes & $2(66.7 \%)$ & $1(33.3 \%)$ & \multirow[t]{2}{*}{0.518} \\
\hline No & 71 (48.0\%) & 77 (52.0\%) & \\
\hline
\end{tabular}

Popliteal fossa thick-walled cystic mass/lesion

$$
\begin{array}{llcrrr}
\text { Yes } & 0(0.0 \%) & 0(0.0 \%) & 3(50.0 \%) & 3(50.0 \%) & 0.660 \\
\text { No } & 2(1.4 \%) & 16(11.0 \%) & 58(40.0 \%) & 69(47.6 \%) &
\end{array}
$$

No augmentation with distal compression

$$
\begin{array}{lccccc}
\text { Yes } & 0(0.0 \%) & 0(0.0 \%) & 1(100.0 \%) & 0(0.0 \%) & 0.610 \\
\text { No } & 2(1.3 \%) & 16(10.7 \%) & 60(40.0 \%) & 72(48.0 \%) &
\end{array}
$$

Distended superficial veins with intraluminal echoes/thrombi

$\begin{array}{cccccc}\text { Yes } & 0(0.0 \%) & 0(0.0 \%) & 0(0.0 \%) & 1(100.0 \%) & 0.685 \\ \text { No } & 2(1.3 \%) & 16(10.7 \%) & 61(40.7 \%) & 71(47.3 \%) & \\ \text { Lower limb ulceration } & & & & \\ \text { Yes } & 0(0.0 \%) & 1(33.3 \%) & 2(66.7 \%) & 0(0.0 \%) & 0.225 \\ \text { No } & 2(1.4 \%) & 15(10.1 \%) & 59(39.9 \%) & 72(48.6 \%) & \end{array}$

\footnotetext{
${ }^{*}$ Statistically significant
}

Table 4 Gender distribution of ultrasound features of our participants 
Table 5 Distribution showing the relationship between age and ultrasound diagnosis

\begin{tabular}{|c|c|c|c|c|c|}
\hline Variable & Age & & & & \\
\hline Diagnosis & $\leq 18$ years & $\begin{array}{l}19- \\
39 \text { years }\end{array}$ & $\begin{array}{l}40- \\
60 \text { years }\end{array}$ & $>60$ years & $P$ value \\
\hline
\end{tabular}

Inguinal lymphadenopathy

$\begin{array}{llllll}\text { Yes } & 0(0.0 \%) & 4(12.1 \%) & 16(48.5 \%) & 13(39.4 \%) & 0.519\end{array}$

No $\quad 2(1.7 \%) \quad 12(10.3 \%) \quad 43(37.1 \%) \quad 59(50.9 \%)$

Cellulitis

$\begin{array}{llllll}\text { Yes } & 0(0.0 \%) & 2(4.3 \%) & 16(34.0 \%) & 29(61.7 \%) & \mathbf{0 . 0 4 7}\end{array}$

No $\quad 2(1.9 \%) \quad 14(13.5 \%) \quad 45(43.3 \%) \quad 43(41.3 \%)$

Deep vein thrombosis

$$
\begin{array}{llllll}
\text { Yes } & 0(0.0 \%) & 2(9.5 \%) & 10(47.6 \%) & 9(42.9 \%) & 0.789
\end{array}
$$

No $\quad 2(1.5 \%) \quad 14(10.8 \%) \quad 51(39.2 \%) 63(48.5 \%)$

Varicose veins

$$
\begin{array}{lccrrr}
\text { Yes } & 0(0.0 \%) & 0(0.0 \%) & 2(40.0 \%) & 3(60.0 \%) & 0.714 \\
\text { No } & 2(1.4 \%) & 16(11.0 \%) & 59(40.4 \%) & 69(47.3 \%) &
\end{array}
$$

* Statistically significant

which is contrary to what was reported by Maheshwar et al. Laterality of the affected side varies from study to study, and no particular reason has been reported from the reviewed literature [19].

\section{Limitation}

The relatively small sample size used may be a limitation for this study. The inherent nature of this retrospective study limited the acquisition of the duration of onset of lower limb swelling for some patients further contributing to the small sample size. Also, in tandem with a

\begin{tabular}{|c|c|c|c|}
\hline \multirow{2}{*}{$\begin{array}{l}\text { Variable } \\
\text { Diagnosis }\end{array}$} & \multicolumn{3}{|l|}{ Sex } \\
\hline & Male & Female & $P$ value \\
\hline \multicolumn{4}{|c|}{ Inguinal lymphadenopathy } \\
\hline Yes & $14(42.4 \%)$ & $19(57.6 \%)$ & \multirow[t]{2}{*}{0.441} \\
\hline No & $59(50.0 \%)$ & $59(50.0 \%)$ & \\
\hline \multicolumn{4}{|l|}{ Cellulitis } \\
\hline Yes & $25(53.2 \%)$ & $22(46.8 \%)$ & \multirow[t]{2}{*}{0.423} \\
\hline No & $48(46.2 \%)$ & $56(53.8 \%)$ & \\
\hline \multicolumn{4}{|c|}{ Deep vein thrombosis } \\
\hline Yes & $8(38.1 \%)$ & $13(61.9 \%)$ & \multirow[t]{2}{*}{0.311} \\
\hline No & $65(50.0 \%)$ & $65(50.0 \%)$ & \\
\hline \multicolumn{4}{|c|}{ Varicose veins } \\
\hline Yes & $2(40.0 \%)$ & $3(60.0 \%)$ & \multirow[t]{2}{*}{0.703} \\
\hline No & $71(48.6 \%)$ & $75(51.4 \%)$ & \\
\hline \multicolumn{4}{|c|}{ Popliteal cyst/baker's cyst } \\
\hline Yes & $2(33.3 \%)$ & $4(66.7 \%)$ & \multirow[t]{2}{*}{0.448} \\
\hline No & 71 (49.0\%) & $74(51.0 \%)$ & \\
\hline \multicolumn{4}{|c|}{ Superficial thrombophlebitis } \\
\hline Yes & $1(100.0 \%)$ & $0(0.0 \%)$ & \multirow[t]{2}{*}{0.227} \\
\hline No & $72(48.0 \%)$ & $78(52.0 \%)$ & \\
\hline \multicolumn{4}{|c|}{ Lower limb pyomyositis } \\
\hline Yes & $2(66.7 \%)$ & $1(33.3 \%)$ & \multirow[t]{2}{*}{0.518} \\
\hline No & $71(48.0 \%)$ & $77(52.0 \%)$ & \\
\hline \multicolumn{4}{|c|}{ Lymphatic obstruction } \\
\hline Yes & $2(66.7 \%)$ & $1(33.3 \%)$ & \multirow[t]{2}{*}{0.518} \\
\hline No & 71 (48.0\%) & $77(52.0 \%)$ & \\
\hline
\end{tabular}

Table 6 Distribution showing the relationship between gender and ultrasound diagnoses

multidisciplinary approach to evidence-based clinical investigation and patient care, biochemical correlates of these ultrasonographic findings deserve some attention as a follow-up study.

\section{Conclusion}

Multiple inguinal lymphadenopathy was the most recurrent ultrasound feature. Edema with thickened skin and subcutaneous layers and cellulitis the most common diagnosis both increased significantly with age. Sonographers, sonologists, and radiologists must be on the lookout for these in their practices. 
Table 7 Distribution showing the relationship between laterality and ultrasound findings

\begin{tabular}{|c|c|c|c|}
\hline \multirow{2}{*}{$\begin{array}{l}\text { Variable } \\
\text { Diagnosis }\end{array}$} & \multicolumn{3}{|c|}{ Laterality (the lower limb affected) } \\
\hline & Right lower limb & Left lower limb & $P$ value \\
\hline \multicolumn{4}{|c|}{ Inguinal lymphadenopathy } \\
\hline Yes & $16(48.5 \%)$ & $17(51.5 \%)$ & 0.716 \\
\hline No & $53(44.9 \%)$ & $65(55.1 \%)$ & \\
\hline \multicolumn{4}{|l|}{ Cellulitis } \\
\hline Yes & $24(51.1 \%)$ & $23(48.9 \%)$ & 0.373 \\
\hline No & $45(43.3 \%)$ & $59(56.7 \%)$ & \\
\hline \multicolumn{4}{|c|}{ Deep vein thrombosis } \\
\hline Yes & $9(42.9 \%)$ & $12(57.1 \%)$ & 0.778 \\
\hline No & $60(46.2 \%)$ & $70(53.8 \%)$ & \\
\hline \multicolumn{4}{|c|}{ Varicose veins } \\
\hline Yes & $3(60.0 \%)$ & $2(40.0 \%)$ & 0.514 \\
\hline No & $66(45.2 \%)$ & $80(54.8 \%)$ & \\
\hline \multicolumn{4}{|c|}{ Popliteal cyst/baker's cyst } \\
\hline Yes & $4(66.7 \%)$ & $2(33.3 \%)$ & 0.291 \\
\hline No & $65(44.8 \%)$ & $80(55.2 \%)$ & \\
\hline \multicolumn{4}{|c|}{ Superficial thrombophlebitis } \\
\hline Yes & $0(0.0 \%)$ & $1(100.0 \%)$ & 0.268 \\
\hline No & $69(46.0 \%)$ & $81(54.0 \%)$ & \\
\hline \multicolumn{4}{|c|}{ Lower limb pyomyositis } \\
\hline Yes & $1(33.3 \%)$ & $2(66.7 \%)$ & 0.660 \\
\hline No & $68(45.9 \%)$ & $80(54.1 \%)$ & \\
\hline \multicolumn{4}{|c|}{ Lymphatic obstruction } \\
\hline Yes & $0(0.0 \%)$ & $3(100.0 \%)$ & 0.116 \\
\hline No & $69(46.6 \%)$ & $79(53.4 \%)$ & \\
\hline
\end{tabular}

\section{Abbreviations}

DVT: Deep Vein Thrombosis; MRI: Magnetic Resonance Imaging; CT: Computed Tomography; IPG: Impedance Plethysmography; CCTH: Cape Coast Teaching Hospital; LHIMS: Lightwave Health Information Management System.

\section{Acknowledgements}

The management of CCTH and the staff of the radiology department of the CCTH are appreciated for their support in making this study successful.

\section{Authors' contributions}

EKME, KDT, EKB, and PNG contributed substantially to the conception, design, implementation of this article, and to the write-up, revision and approval of the manuscript for publication. FNG, ATA, PA, MKA, EAI, MA, and OC contributed substantially to the design, data collection and analysis, to the write-up, revision and approval of the manuscript for publication. EB, JMK, FQ, RAE, and ARA contributed substantially to the design, literature searches, data collection and analysis, to the write-up, editing, revision, and approval of the manuscript for publication. All authors read and approved the final manuscript.

\section{Funding}

None secured.

\section{Availability of data and materials}

The data used to support the findings of this article may be released upon request to the Head of the Research Unit of the Cape Coast Teaching Hospital. Postal address is as follows: P.O. Box CT I363, Cape Coast, Ghana. E-mail is ccthresearch@gmail.com.

\section{Declarations}

\section{Ethics approval and consent to participate}

Ethical clearance number (CCTHERC/EC/2020/095) was approved for this study by the Ethical Review Committee of CCTH. Anonymity and confidentiality were ensured throughout the study. This study conformed to the 1975 Declaration of Helsinki.

\section{Consent for publication \\ Not applicable.}

\section{Competing interests}

No conflict of interest to declare.

\section{Author details}

${ }^{1}$ Department of Medical Imaging, School of Medical Sciences, College of Health and Allied Sciences, University of Cape Coast, Cape Coast, Ghana. ${ }^{2}$ Department of Radiology, Cape Coast Teaching Hospital, Cape Coast, Ghana. ${ }^{3}$ Department of Radiology, Korle Bu Teaching Hospital, 1 Guggisberg Avenue, Accra, Ghana. ${ }^{4}$ Department of Radiology, University of Ghana Medical School, Accra, Ghana. ${ }^{5}$ Department of Chemical Pathology, School of Medical Sciences, College of Health and Allied Sciences, University of Cape Coast, Cape Coast, Ghana. ${ }^{6}$ Department of Radiology, School of Medical Sciences, College of Health Sciences, Kwame Nkrumah University of Science and Technology, Kumasi, Ghana. ${ }^{7}$ Department of Surgery, School of Medical Sciences, College of Health and Allied Sciences, University of Cape Coast, Cape Coast, Ghana. ${ }^{8}$ Department of Radiology, 37 Military Hospital, Neghelli Barracks Liberation Road 37, Accra, Ghana. ${ }^{9}$ Department of Family Medicine, Geriatric Unit, University of Cape Coast Hospital, Cape Coast, Ghana. ${ }^{10}$ Department of Microbiology and Immunology. School of Medical Sciences, College of Health and Allied Sciences, University of Cape Coast, Cape Coast, Ghana. ${ }^{11}$ African Institute for Mathematical Sciences (AIMS), Summerhill Estates, East Legon Hills, Santoe, Accra, Ghana.

Received: 4 October 2021 Accepted: 22 November 2021

Published online: 29 November 2021

\section{References}

1. Simon EB (2014) Leg edema assessment and management. Medsurg Nurs 23(1):44-53 (PMID: 24707668)

2. Gasparis AP, Kim PS, Dean SM, Khilnani NM, Labropoulos N (2020) Diagnostic approach to lower limb edema. Phlebology 35(9):650-655. https:// doi.org/10.1177/0268355520938283

3. Mutluer FO, İndelen C, Dinçer N, Aslan G, Ateş MŞ (2018) Unilateral leg edema: Is it always vascular? Arch Turk Soc Cardiol 46(8):706-709. https:// doi.org/10.5543/tkda.2018.85601

4. Easterbrook J, Walker MA (2002) The unilateral swollen lower limb: etiology, investigation, and management. Int J Low Extrem Wounds 1(4):242-250. https://doi.org/10.1177/1534734602239750

5. Bekou V, Galis D, Traber J (2011) Unilateral leg swelling: deep vein thrombosis? Phlebology 26(1):8-13. https://doi.org/10.1258/phleb.2009.009055

6. Elgendy IY, LO MC (2014) Case report: unilateral lower extremity swelling as a rare presentation of non-Hodgkin's lymphoma. BMJ Case Rep 2014:2013-202424. https://doi.org/10.1136/bcr-2013-202424

7. Naidich JB, Feinberg AW, Karp-Harman H, Karmel MI, Tyma CG, Stein HL (1988) Contrast venography: reassessment of its role. Radiology 168(1):97-100. https://doi.org/10.1148/radiology.168.1.3289098

8. Aywak AA, Masesa JV (2007) Comparison of sonography with venography in the diagnosis of deep venous thrombosis. East Afr Med J 84(7):304-311. https://doi.org/10.4314/eamj.v84i7.9584

9. Hotoleanu C, Fodor D, Suciu O (2010) Correlations between clinical probability and Doppler ultrasound results in the assessment of deep venous thrombosis. Med Ultrason 12(1):17-21

10. Mangeni F, Kawooya MG, Kiguli-Malwadde E, Ssali F (2006) Sonography and risk factors for lower limb deep venous thrombosis at Mulago hospital. Uganda East African Med J 83(8):443-449. https://doi.org/10.4314/ eamj.v83i8.9460 
11. Edzie EKM, Dzefi-Tettey K, Gorleku PN, Amankwa AT, Aidoo E, AgyenMensah K, Idun EA, Quarshie F, Kpobi JM, Kusodzi H, Edzie RA (2021) Evaluation of the clinical and imaging findings of breast examinations in a tertiary facility in Ghana. Int J Breast Cancer 19:2021. https://doi.org/10. $1155 / 2021 / 5541230$

12. Malgor RD, Labropoulos N (2013) Diagnosis of venous disease with duplex ultrasound. Phlebology 28:158-161. https://doi.org/10.1177/ 0268355513476653

13. Mendoza E (2015) Duplex ultrasound in the diagnosis of acute legswelling. Rev Vasc Med 3(2):17-23. https://doi.org/10.1016/j.rvm.2015.05. 002

14. Paramesparan K, lqbal A, Shah A, Botchu R (2019) Imaging of the unilateral swollen painful lower leg: deep vein thrombosis mimics. Indian J Musculoskelet Radiol 1(1):27-40. https://doi.org/10.25259/JMSR_15_ 2019

15. Sutter ME, Turnipseed SD, Diercks DB, Samuel P, White RH (2009) Venous ultrasound testing for suspected thrombosis: incidence of significant non-thrombotic findings. J Emerg Med 36(1):55-59. https://doi.org/10. 1016/j.jemermed.2007.08.066

16. Lockhart ME, Sheldon HI, Robbin ML (2005) Augmentation in lower extremity sonography for the detection of deep venous thrombosis. Am J Roentgenol 184(2):419-422. https://doi.org/10.2214/ajr.184.2.01840419

17. Khaladkar SM, Thakkar DK, Shinde K, Thakkar DK, Shrotri H, Kulkarni VM (2014) Deep vein thrombosis of the lower limbs: A retrospective analysis of doppler ultrasound findings. Med J Dr. DY Patil Univ 7(5):612

18. Boyd DA (2004) Unilateral lower extremity edema in May-Thurner syndrome. Mil Med 169(12):968-971. https://doi.org/10.7205/MILMED.169. 12.968

19. Baz AA, Hassan TA (2018) Imaging of acute unilateral limb swelling: a multi modality overview. Egypt J Radiol Nucl Med 49(2):419-434. https:// doi.org/10.1016/j.ejrnm.2018.02.011

20. Maheshwar A, Ramprasath R (2020) Prospective study on risk factor for unilateral oedema of leg. Int J Surg 4(2):283-285

21. Garcia R, Labropoulos N (2018) Duplex ultrasound for the diagnosis of acute and chronic venous diseases. Surg Clin North Am 98(2):201-218. https://doi.org/10.1016/j.suc.2017.11.007

22. Hamper UM, DeJong MR, Scoutt LM (2007) Ultrasound evaluation of the lower extremity veins. Radiol Clin North Am 45(3):525-547. https://doi. org/10.1016/j.rcl.2007.04.013

23. Cnop M, Havel PJ, Utzschneider KM, Carr DB, Sinha MK, Boyko EJ, Retzlaff BM, Knopp RH, Brunzell JD, Kahn SE (2003) Relationship of adiponectin to body fat distribution, insulin sensitivity and plasma lipoproteins: evidence for independent roles of age and sex. Diabetologia 46(4):459-469. https://doi.org/10.1007/s00125-003-1074-z

24. Burhans MS, Hagman DK, Kuzma JN, Schmidt KA, Kratz M (2019) Contribution of adipose tissue inflammation to the development of type 2 diabetes mellitus. Compr Physiol 9(1):1-58. https://doi.org/10.1002/cphy. c170040

25. Jenkins TC, Knepper BC, Jason Moore S, Saveli CC, Pawlowski SW, Perlman DM, McCollister BD, Burman WJ (2014) Comparison of the microbiology and antibiotic treatment among diabetic and nondiabetic patients hospitalized for cellulitis or cutaneous abscess. J Hosp Med 9(12):788-794. https://doi.org/10.1002/jhm.2267

\section{Publisher's Note}

Springer Nature remains neutral with regard to jurisdictional claims in published maps and institutional affiliations.

\section{Submit your manuscript to a SpringerOpen ${ }^{\odot}$ journal and benefit from:}

- Convenient online submission

- Rigorous peer review

- Open access: articles freely available online

- High visibility within the field

- Retaining the copyright to your article

Submit your next manuscript at $\boldsymbol{\nabla}$ springeropen.com 